DE

M E D I C I N A

T R O P I C A L

$\mathrm{DE}$

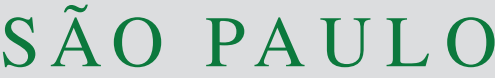

JOURNAL OF THE SÃO PAULO INSTITUTE OF TROPICAL MEDICINE

${ }^{1}$ Fundação Oswaldo Cruz, Instituto Oswaldo Cruz, Laboratório de Microbiologia Celular, Rio de Janeiro, Rio de Janeiro, Brazil

2Universidade Federal de São Paulo, Instituto de Ciências Farmacêuticas, São Paulo, São Paulo, Brazil

Correspondence to: Maria Helena Féres Saad

Fundação Oswaldo Cruz, Instituto Oswaldo Cruz, Laboratório de Microbiologia Celular, Av. Brasil, 4365, CEP 21040-360, Rio de Janeiro, RJ, Brazil

Tel: +55 21.2562-1598

E-mail: maria.saad03@gmail.com

Received: 28 December 2018

Accepted: 18 April 2019

\section{Usefulness of 3'- 5' IS6110-RFLP genotyping and spoligotyping of Mycobacterium tuberculosis isolated in a tertiary hospital: a retrospective study detecting unsuspected epidemiological events}

\author{
Silvia Maria de Almeida ${ }^{1}$, Ana Carolina Malaspina ${ }^{2}$, Clarisse Queico Fujimura \\ Leite $^{2}$, Maria Helena Féres Saad ${ }^{(1)}$
}


of TB retreatment ${ }^{5}$ and with one-third of TB cases being reported in hospitals ${ }^{6}$. A survey carried out from 1996 to 1998 at the Pedro Ernesto University Hospital (HUPE), which, as a tertiary health service received patients from different geographic areas of RJ, indicated an isoniazidresistant M. tuberculosis rate of $13 \% 5$.

Genotyping methods, such as spoligotyping and RFLP, are performed to understand TB transmission. These routine approaches are used in several developed countries, while molecular studies are punctual in developing countries and usually only one genotyping method is used. Spoligotyping is less powerful for cluster investigations than IS6110-RFLP. Nevertheless, if strains are isolated from patients coming from different geographic areas, cluster definition failures may occur, as the restriction sites may be located in different points throughout the IS6110 sequence on the bacterial genome. This is due to genetic mechanisms that can lead to loss of the restriction site flanking the IS6110 insertion, compromising case grouping. An alternative method that increases the probability of grouped strains actually being related clones, especially if strains are isolated from unrelated geographic areas, has been described using the 5' IS6110 probe $^{7}$. Briefly, the physical IS 6110 map indicates a single Pvu II restriction site that has been successfully applied to the cleavage of these sequences in order to obtain two IS 6110 restriction fragments of different sizes, reflecting polymorphisms between strains. The right side of the $P v u$ II restriction site was arbitrarily chosen for the standardization of RFLP genotyping by reducing the number of $I S 6110$ fragments to the half. In some cases, for a better differentiation between strain patterns, membranes could be re-hybridized with labeled DNA probes containing only of the IS6110 fragment on the left of the $P v u I I$ restriction site ${ }^{8}$ (Figure 1). On the other hand, the RFLP-IS6110, despite being more laborious than the MIRU-VNTR, a PCR based method using 12 or 24 interspaced markers, or spoligotyping, requiring higher amounts of DNA, has the advantage of a strong genetic stability, which makes this technique appropriate to identify true clusters in old population strains ${ }^{9}$.

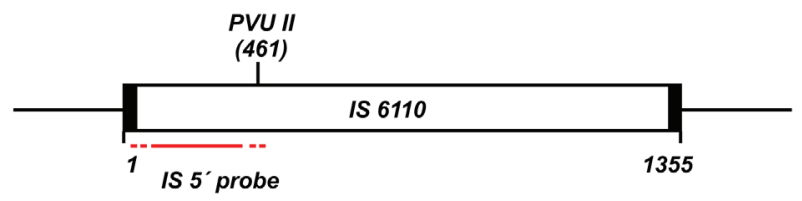

IS 3' probe

Figure 1 - Schematic representation of the 6110 insertion sequence (IS), present in the Mycobacterium tuberculosis genome, cleaved by the Pvu // endonuclease yielding two fragments ${ }^{8}$ used as probes in restriction fragment length polymorphism 3' IS6110 and 5' IS6110 genotyping studies.
In the present study, taking the advantage of data availability and isolates from HUPE patients, a retrospective cluster investigation by 3' - 5' IS6110- RFLP is reported, using the same membrane and the spoligotyping scenario on phylogenetic diversity. Clusters defined by all methods and the investigated epidemiological relationships provided a snapshot of past epidemiological events.

\section{MATERIAL AND METHODS}

\section{Study site, patients and M. tuberculosis isolates}

Despite its location in the Vila Isabel neighborhood, in the Rio de Janeiro city, HUPE receives patients from several other municipalities, as well as other States, since it is a referral center for AIDS treatment, as well as for many primary and secondary health care units. From August 1996 to February 1998, the hospital had 604 beds and presented an estimated $350 \mathrm{~TB}$ cases diagnosed per year. However, the hospital presented no respiratory isolation beds and no TB control actions ${ }^{5}$. A total of 415 isolates from 248 patients identified in the previous study, were subcultured in Löwenstein Jensen's medium (LJ) and 125 growths (30.1\%) from $106(43 \%)$ patients from different neighborhoods and municipalities in Rio de Janeiro were obtained. Multiple isolates (36/125) were obtained from 17 patients (Figure 2). Most of these patients harbored two isolates, except for two, which presented three isolates each. Of the total number of isolates, $70 \%$ belonged to outpatients, while the remaining patients spent an average of $14.6 \pm 13.1$ days in the hospital. Most individuals sought HUPE care with suspected pulmonary TB $(83 \%)$.

Previously, biochemical tests, (positive niacin production, positive nitrate reductase activity and negative catalase thermal-inactivation), identified the M. tuberculosis complex (MTBC), while drug susceptibility testing (DST) to isoniazide $(\mathrm{H})$, rifampicin $(\mathrm{R})$, pyrazinamide $(\mathrm{Z})$, streptomycin (S), ethambutol (Eb) and ethionamide (Et) was performed by the standard proportion method in LJ medium, at the Central Noel Nutels Laboratory (LACENN), $\mathrm{RJ}^{10}$. Socio-demographic, clinical and laboratory data analyses were carried out by assessing the patients' medical records. No contact or personal interviews were performed with patients to obtain additional information. This study was approved by the HUPE Research Ethics Committee.

\section{Molecular typing}

CTAB-DNA based extraction was performed ${ }^{11}$ in 113 isolates from 95 patients, while thermolysis extraction was carried out for the remaining isolates ${ }^{12}$. Spoligotyping 


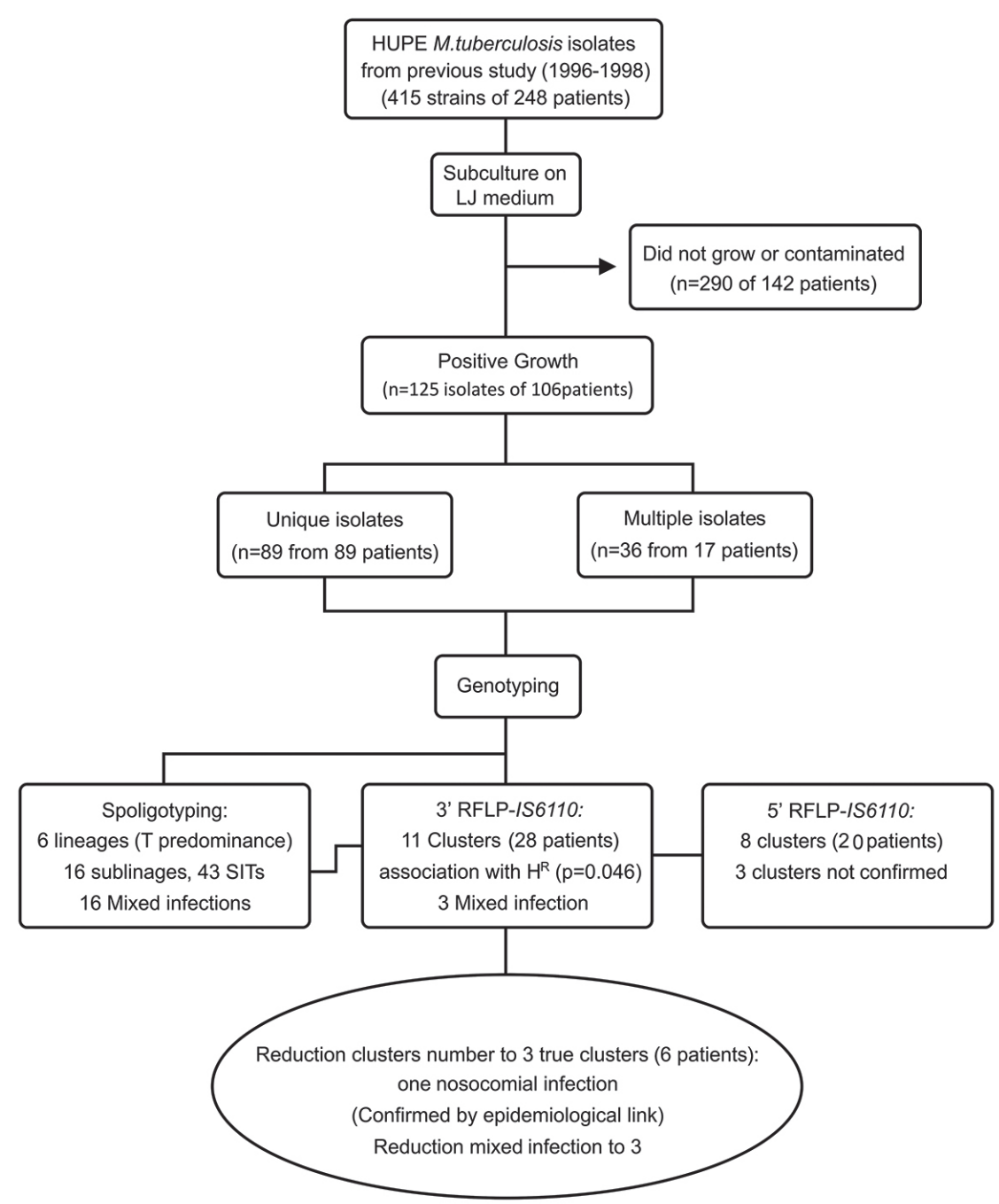

Figure 2 - Flowchart on the recovery of $M$. tuberculosis isolates of TB patients attended at the tertiary Pedro Ernesto University Hospital, Rio de Janeiro, Brazil, 1996-1998, and the main genotyping results.

follow the Kamerbeek et al. ${ }^{13}$ protocol, using spoligomembranes from Ocimum Biosolutions Ltda (Hyderabad, India). An overestimation of the number of potentially related isolates is a possibility, as the discriminatory power of spoligotyping is lower and patients were from unrelated communities. Thus, 3' IS6110-RFLP-based typing was applied. The clusters obtained by this method were also 5' IS6110-RFLP typed. The 3' IS6110-RFLP technique was carried out as previously described ${ }^{8,14}$. The 5' IS6110-RFLP method was performed as described elsewhere ${ }^{15,16}$, with minor modifications. Briefly, probe hybridization was carried out on the same 3' IS6110 assayed membranes after removal of the precipitated blue color and the 3' probe by heating the membranes at $50-60{ }^{\circ} \mathrm{C}$ in pure dimethylformamide (Dig nucleic acid detection kit, Roche, USA). The positive and negative controls for each experiment were the ATCC 14323 M. tuberculosis and an M. avium clinical isolate, respectively. Laboratory cross-contamination was ruled out through verification that isolates with an identical fingerprint pattern had not been processed on the same day. To avoid risks of crosscontamination during cultivation and preparation of clinical samples for genotyping, all sample processing took place in laminar flow cabinets and only a limited number of specimens were processed on the same day.

\section{Data analyses}

Spoligotyping patterns were documented as octal and binary codes and compared to the SITVIT2 proprietary database $^{17}$ an updated version of the SITVITWEB database $^{18}$. The Spoligotype International Type (SIT) classification designates identical patterns shared with at least one other profile present in the database, while "orphan" patterns are applied for a single isolate that does not present any homology among patterns recorded in the 
repository database. New spoligo patterns, whether orphan or encountered in multiple isolates in the present population, were repeated. Phylogenetic lineage identification was according to the signature provided by the database, defining 62 genetic lineages/sublineages. Georeferenced data allowed the identification of the geographic location of the spoligopatterns, as well as of true-clustered patients, through the home address of each patient (Figure 3). Spoligotypes and 3' and 5' IS6110-RFLP patterns were analyzed by the Bionumerics 5.3 (Applied Maths, NV, Sint-MartensLatem, Belgium) and/or GelCompar 3.1 (Applied Maths, Kortrijk, Belgium) softwares and supplemented visually. Cluster definition was two or more patients infected with M. tuberculosis harboring the same genotype obtained by the spoligotyping and 3' IS6110 methods. However, true clusters were assigned to those with the same genotype patterns

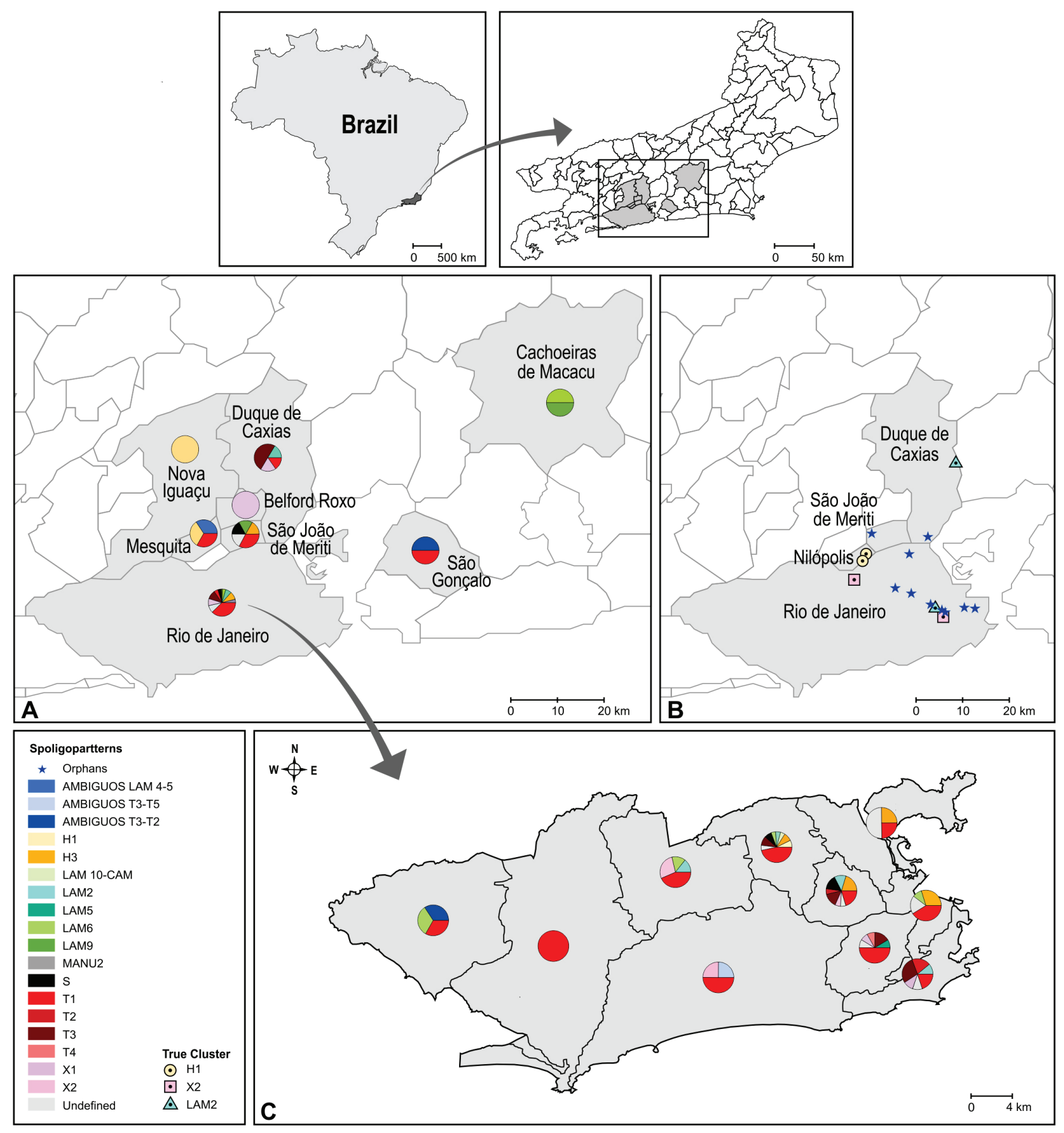

Figure 3 - Espatial georeferenced distribution of genotyped M. tuberculosis strains isolated from patients attended at the Pedro Ernesto University Hospital in Rio de Janeiro, Brazil, 1996-1998: A) Rio de Janeiro State; B) true clustered patients defined by 3' - 5' IS 6110-RFLP and spoligotype, and orphans spoligopaterns; C) Rio de Janeiro city. 
combining all three methods, followed by epidemiological link assessments. Statistical significance between categorical variables was Chi-square estimated by Yates correction and an odds ratio at a 95\% confidence interval, in order to establish associations among the clustered patients. The discriminatory power of 3' RFLP IS 6110 was calculated by applying the numeric discriminatory index (HGDI), as suggested by Hunter and Gaston ${ }^{19}$.

\section{RESULTS}

The spoligotyping method distributed the isolates into six lineages and 16 sub-lineages, as displayed in Figure 4. Most belonged to the ill-defined T spoligotype (68/125, $54.4 \%$ ), which predominates in different Rio de Janeiro neighborhoods, including $73 \%$ of the orphan SIT patterns. The $\mathrm{H}$ and LAM, X, S and Manu2 lineages were less frequent $(\geq 12.8 \%)$. Surprisingly, the usually low banding $\mathrm{X}$ clade presented two strains with higher copy numbers $(>10)$. One new spoligopattern signature $(0.8 \%)$ was identified. Four new shared types resulting from this study were created in the database, SIT1906 (LAM6), SIT1907 (Ud), SIT1909 (T1) and SIT1911 (T3). Different SITs $(n=43)$ and 88/125 $(70.4 \%)$ isolates belonged to 23 groups. The largest genetic group comprised 15 isolates of the ubiquitous SIT53 (17\%), followed by 10 isolates presenting Asian or African spoligotype (11.4\%), belonging to the T1 sub-lineage, which also predominated in six other genetic groups from two patients. It is noteworthy that most of drug-resistant isolates were from the $\mathrm{T} 1$ lineage



Figure 4 - Spoligotype patterns and number of shared international typing (SIT) of $125 \mathrm{M}$. tuberculosis strains isolated from 106 patients attended at the Pedro Ernesto University Hospital, Rio de Janeiro, Brazil, 1996-1998. 
(22/58), with a third (31.8\%) from the SIT 535. Risk factors were not identified although most MDR (2/3) and multiple resistant (4/6) isolates belonged to the $\mathrm{T}$ lineage. The remaining MDR were LAM2/SIT179 and belonged to a polyclonal infection case. Spoligotyping identified polyclonal infections among all $17 \mathrm{~TB}$ diagnosed patients who displayed multiple sputum isolates. However, the RFLP 3' IS 6110 genotyping confirmed mixed infection in only 3/17 patients, including the MDR LAM2/SIT179 strain (Table 1). It is important to mention that only one specimen was processed on the same day as other specimens from the study, minimizing the risk of cross contamination.

The 3' IS6110-RFLP method defined 28/95 (29.5\%) patients distributed in 11 clusters, most containing two patients, except for three clusters, one comprising four patients and two, five patients each. No isolates presented only one copy number or none. The discriminatory power of the 3' IS 6110-RFLP method was 0.986. The available demographic, clinical, and DST characteristics of the patients with strains genotyped by the 3' IS 6110-RFLP method are summarized in Table 2. The analysis regarding possible risk factors did not identify significant cluster associations, except for $\mathrm{H}^{\mathrm{R}}(\mathrm{p}=0.046)$.

The 5' IS6110-RFLP method, performed for 10/11 clusters from 25 patients and did not confirm three 3' IS6110 clusters. One of the clusters containing four patients was excluded, while the other clusters comprising two patients each were split. Thus, 20 patients distributed into eight clusters remained (Table 3, Figure 2). However, combining the clusters obtained by spoligotyping, 3' and 5' IS6110-RFLP resulted in a dramatic decrease in cluster isolates $(n=6 ; 6 \%)$, distributed into three true clusters with two patients each, one of them characterized as a nosocomial transmission event (Figure 2). Among the 3' IS6110-RFLP clusters, three were subdivided by the 5' IS6110-RFLP method, and only six patients remained clustered by spoligotyping. It is interesting to note that, among patients with low banding patterns who were all clustered by both RFLP probes, only $2 / 7$ remained grouped by the spoligotyping method (Table 4). Although both patients were infected with resistant strains, no detectable evidence of an epidemiological relationship was observed. The nosocomial transmission was discovered involving two patients with immunosuppression due to chronic degenerative diseases. Both presented type II diabetes and one suffered from laryngeal cancer and dermatomyositis. They live in the same municipality, but in different neighborhoods, at a distance of approximately $3.9 \mathrm{~km}$. However, both underwent several HUPE hospitalizations and, in 1996, they met each other as outpatients undergoing treatment in the dermatology service. A 65-year-old patient, hospitalized from 6/26/1996 to 10/10/1996, with negative smear microscopy and bronchoalveolar lavage culture, aside from a radiography showing a pulmonary inflammatory infiltrate was discharged with a corticoid prescription. This patient returned 5 months later $(03 / 11 / 1997)$ presenting changes of X-ray images indicative of TB and a positive AFB sputum smear, initiating the TB specific treatment but

Table 1 - Genotypic patterns from Mycobacterium tuberculosis isolates defined by spoligotype and 3' IS 6110-RFLP and data from patients harboring mixed Infections who attended the tertiary Pedro Ernesto Universty Hospital (1996-1998)

\begin{tabular}{|c|c|c|c|c|c|c|c|c|c|}
\hline Age & Sex & Unity & $\begin{array}{l}\text { Inpatient } \\
\text { Time } \\
\text { (days) }\end{array}$ & $\begin{array}{l}\text { Neigborhood/ } \\
\text { Municipality }\end{array}$ & $\begin{array}{l}\text { Isolation } \\
\text { Data }\end{array}$ & DST & Spoltype (SIT/Sublineage) & 3' IS6110-RFLP pattern & Remarks \\
\hline \multirow{2}{*}{29} & \multirow{2}{*}{$F$} & \multirow{2}{*}{ PN } & \multirow{2}{*}{ - } & \multirow{2}{*}{ Leblon/RJ } & $10 / 16 / 96$ & MDR & $\begin{array}{l}\text { (179/LAM2) } \\
\end{array}$ & 1 in m & \multirow{2}{*}{$\begin{array}{l}\text { Caregiver, } \\
\text { Black, } \\
\text { BCG scar, } \\
\text { Born in RJ }\end{array}$} \\
\hline & & & & & $11 / 13 / 96$ & $\mathrm{MDR}+\mathrm{Et}^{\mathrm{R}}$ & " & III III II I I & \\
\hline \multirow{2}{*}{30} & \multirow{2}{*}{ M } & \multirow{2}{*}{ PN } & \multirow{2}{*}{9} & \multirow{2}{*}{ WI } & 08/13/96 & S & (1163/T1) & t nat 1 un & \multirow{2}{*}{$\begin{array}{c}\text { White, } \\
\text { - Sm, born in } \\
\text { RJ }\end{array}$} \\
\hline & & & & & 09/13/96 & S & $\begin{array}{l}\text { (53/T1) } \\
\end{array}$ & all in in & \\
\hline \multirow{3}{*}{15} & \multirow{3}{*}{$\mathrm{F}$} & \multirow{3}{*}{ DIP } & \multirow{3}{*}{18} & \multirow{3}{*}{ Cascadura/RJ } & 08/01/97 & S & (50/H3) & ND & \multirow{3}{*}{$\begin{array}{c}\text { Student, } \\
\text { Black, BCG } \\
\text { scar, born in } \\
\text { RJ, bronchitis }\end{array}$} \\
\hline & & & & & $08 / 13 / 97$ & S & (535/T1) & a & \\
\hline & & & & & 09/05/97 & S & (Orphan/T1) & 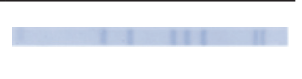 & \\
\hline
\end{tabular}

F: female; M: male; PN :pneumology clinic; DIP: infectious diseases parasitic clinic; WI: without information; RJ: Rio de Janeiro; DST: drug susceptibility test; Et ${ }^{R}$ : ethionamide resistant; S: susceptible; MDR: resistant at least to isoniazid and rifampicin; N: no; BCG: Bacille Calmette Guèrin vaccine scar; Sm: smoker; SIT: sheared international typing; ND: not done. 
Table 2 - Clinical, demographic and laboratory features of clustered and no clustered patients of Pedro Ernesto University Hospital by 3' IS 6110-RFLP, from August 1996 to February 1998, Rio de Janeiro, Brazil

\begin{tabular}{|c|c|c|c|c|}
\hline Features & $\begin{array}{c}\text { Cluster } \\
\mathrm{N}=28(\%)\end{array}$ & $\begin{array}{l}\text { No cluster } \\
\mathrm{N}=67(\%)\end{array}$ & $\begin{array}{l}\text { Odds Ratio (OR) } \\
(\mathrm{Cl}-95 \%)\end{array}$ & $p$ value \\
\hline Age as $x(D P)^{1}$ & $39.7(14)$ & $40.5(11)$ & $1.37(0.11-15.83)$ & 0.68 \\
\hline $\begin{array}{l}\text { Genus } \\
\text { Male } \\
\text { Female }\end{array}$ & $\begin{array}{l}19(68) \\
9(32)\end{array}$ & $\begin{array}{l}53(79) \\
14(21)\end{array}$ & $\begin{array}{c}0.56(0.2-1.4) \\
-\end{array}$ & $\begin{array}{c}0.36 \\
-\end{array}$ \\
\hline $\begin{array}{l}\text { Education Level } \\
\text { Elementary } \\
\text { High school } \\
\text { wi }\end{array}$ & $\begin{array}{c}18(64) \\
0 \\
10(36)\end{array}$ & $\begin{array}{c}50(75) \\
0 \\
17(25)\end{array}$ & $\begin{array}{l}- \\
-\end{array}$ & $\begin{array}{l}- \\
- \\
-\end{array}$ \\
\hline $\begin{array}{l}\text { Alcoholism } \\
\text { Yes } \\
\text { No } \\
\text { wi }\end{array}$ & $\begin{array}{l}6(21) \\
16(57) \\
6(22)\end{array}$ & $\begin{array}{l}26(39) \\
30(45) \\
11(16)\end{array}$ & $\begin{array}{c}0.4(0.14-1.26) \\
1.0 \\
-\end{array}$ & 0.19 \\
\hline $\begin{array}{l}\text { HIV } \\
\text { Seropositive } \\
\text { Seronegative } \\
\text { wi }\end{array}$ & $\begin{array}{c}5(18) \\
11(39) \\
12(43)\end{array}$ & $\begin{array}{l}20(30) \\
29(43) \\
18(27)\end{array}$ & $\begin{array}{c}1.51(0.45-5.04) \\
1.0 \\
-\end{array}$ & 0,69 \\
\hline $\begin{array}{l}\text { Pre-treatment } \\
\text { Yes } \\
\text { No } \\
\text { wi }\end{array}$ & $\begin{array}{c}2(7) \\
12(43) \\
14(50)\end{array}$ & $\begin{array}{l}10(15) \\
36(54) \\
21(31)\end{array}$ & $\begin{array}{c}0.6(0.11-3.13) \\
1.0 \\
-\end{array}$ & 0.78 \\
\hline $\begin{array}{l}\text { Drug susceptibilit } \\
\text { Sensitive } \\
\text { Any Resistance } \\
\text { wi }\end{array}$ & $\begin{array}{c}9(32) \\
14(50) \\
5(18)\end{array}$ & $\begin{array}{c}26(39) \\
35(52) \\
6(9)\end{array}$ & $\begin{array}{c}1.15(0.43-3.07) \\
1.0 \\
-\end{array}$ & 0.96 \\
\hline $\begin{array}{l}\text { Resistance to } \mathrm{H} \\
\text { Resistant } \\
\text { Sensitive } \\
\text { wi }\end{array}$ & $\begin{array}{c}7(25) \\
16(57) \\
5(18)\end{array}$ & $\begin{array}{c}6(9) \\
55(82) \\
6(9)\end{array}$ & $\begin{array}{c}4.01(1,17-13.64) \\
1.0 \\
-\end{array}$ & 0.046 \\
\hline
\end{tabular}

${ }^{1}$ average and standard deviation. $\mathrm{Cl}$ : confidence index; wi: without information; HIV: human immunodeficiency virus; H: isoniazid; RFLP: restriction fragment length polymorphism.

dying three months later (06/07/1997). The other patient, a HUPE cupbearer employee who also suffered multiple hospitalizations in different HUPE wards, presented a marked tuberculin skin test and positive AFB sputum smear, only 31 days (04/16/1997) after the TB diagnosis of the first patient. Patients underwent treatment with TB first line drugs and isolates were $\mathrm{Et}^{\mathrm{R}}$.

The other two clusters displayed no special epidemiological features and no associations could be established, as the patients lived in different neighborhoods far from each other ( $>39 \mathrm{~km}$ ) (Table 3 ). No epidemiological relationships were found for the remained clusters defined by the 3' RFLP probe.

Concerning the possible mixed infection cases, a decrease to three was observed after combining the spoligotyping and the 3' IS6110-RFLP method (Table 1). MDR harboring an extra Et resistance were identified in one of the isolates. The linked patient was BCG scar positive and a TB HUPE inpatient caregiver. The two-sputum exam collections were carried out one month apart, and treatment was initiated with RHZ after the patient has informed never having received treatment for TB. Although this patient may have been involved in a nosocomial transmission event, no reliable epidemiological relationship could be established, since the other patient harboring an isolate with the same clonal pattern developed TB 11 months afterwards, was fully drug sensitive and reported TB treatment 15 years prior to this event. The remaining two polyclonal cases were inpatients for at least nine days, living in different Rio de Janeiro neighborhoods. Both stated that they had never been treated for TB, BCG scars were present and sputum exams on different days/months indicated fully drug susceptible isolates (Table 1).

\section{DISCUSSION}

Retrospective studies focusing on genotyping pattern frequencies provide important data on the relationship 
Table 3 - Characteristics of true-clustered tuberculous patients attended at the tertiary Pedro Ernesto University Hospital in Rio de Janeiro city, $1996-1998$

\begin{tabular}{|c|c|c|c|c|c|c|c|c|c|c|}
\hline ID & Age & Sex & Unity & $\begin{array}{l}\text { Neigborhood/ } \\
\text { Municipality }\end{array}$ & $\begin{array}{c}\text { Data TB } \\
\text { Diagnosis }\end{array}$ & DST & Spoltype (SIT/sublineage) & $\begin{array}{l}\text { 3' IS6110-RFLP } \\
\text { pattern }{ }^{1}\end{array}$ & $\begin{array}{l}5^{\prime} \text { IS6110-RFLP } \\
\text { pattern }\end{array}$ & $\begin{array}{l}\text { Epidemiological } \\
\text { Remark }\end{array}$ \\
\hline $\begin{array}{c}66 \\
123\end{array}$ & $\begin{array}{l}39 \\
67\end{array}$ & $\begin{array}{l}M \\
M\end{array}$ & $\begin{array}{l}\text { PN } \\
\text { WI }\end{array}$ & $\begin{array}{l}\text { P. Miguel/ } \\
\text { RJ\#\#Andarai }\end{array}$ & $\begin{array}{c}5 / 20 / 199 \\
11 / 21 / 1997\end{array}$ & $\mathrm{H}^{\mathrm{R}}, \mathrm{Et}^{\mathrm{R}}$ & 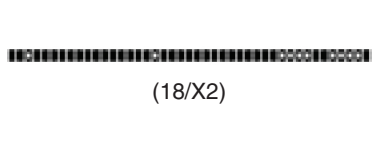 & I & 111 & $\begin{array}{l}\text { Al, Sm, BCG, } \\
\text { Born in PB, } \\
\text { COPD, } \\
\text { Born in RJ }\end{array}$ \\
\hline $\begin{array}{l}55 \\
56\end{array}$ & $\begin{array}{l}51 \\
65\end{array}$ & $\begin{array}{l}M \\
M\end{array}$ & $\begin{array}{l}\text { WI } \\
\text { CM17 }\end{array}$ & $\begin{array}{l}\text { Nilopolis/RJ } \\
\text { P. Anchieta/RJ }\end{array}$ & $\begin{array}{l}04 / 16 / 1997 \\
03 / 18 / 1997\end{array}$ & $\mathrm{Et}^{\mathrm{R}}$ & 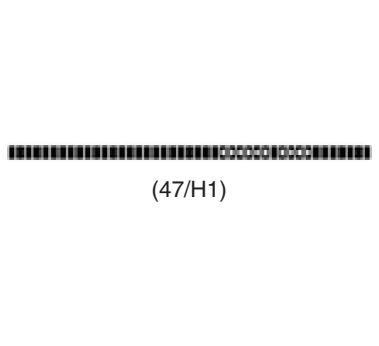 & 11110 & I माना। II & $\begin{array}{l}\text { DM, Al, Sm, } \\
\text { born in RJ, } \\
\text { hospital } \\
\text { cupbearer } \\
\text { DM, LC, DMS, } \\
\text { Al, Sm, } \\
\text { born in RJ } \\
\text { Meet each } \\
\text { other } \\
\text { (Nosocomial) }\end{array}$ \\
\hline $\begin{array}{c}95 \\
145\end{array}$ & $\begin{array}{l}37 \\
\text { WI }\end{array}$ & $\begin{array}{l}\mathrm{F} \\
\mathrm{M}\end{array}$ & $\begin{array}{l}\mathrm{HC} \\
\mathrm{HC}\end{array}$ & $\begin{array}{l}\text { Lins/RJ } \\
\text { Imbarie/DC }\end{array}$ & $\begin{array}{l}09 / 13 / 1997 \\
06 / 17 / 1997\end{array}$ & $\mathrm{~s}$ & 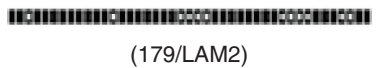 & II IIII III & 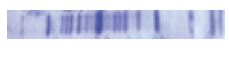 & $\begin{array}{c}\text { BCG, } \\
\text { born in RJ }\end{array}$ \\
\hline
\end{tabular}

ID: patient identification; SIT: shared international typing; RFLP: restriction fragment length polymorphism; M: male; F: female; PN: Pneumology Clinic; HC: Health Care; DST: drug susceptibility test; $\mathrm{H}^{\mathrm{R}}$ and $\mathrm{Et}$ : isoniazid and ethionamide resistant; $\mathrm{S}$ : susceptible; MDR: resistant at least to isoniazid and rifampicin; $\mathrm{N}$ : no; $\mathrm{Y}$ : yes; WI: without information; PB: Paraiba State; BCG: Bacille Calmette Guèrin vaccine scar; Al: alcohol addict; Sm: smoker; COPD: Chronic obstructive pulmonary disease; RJ: Rio de Janeiro; DC: Duque de Caxias; DM: diabetes mellitus; LC: Laryngeal cancer; DMS: Dermatomyositis.

between risk factors and diseases. Scarce studies using spoligotype had been carried out at that time in Brazil so that little is known about the most frequent spoligopatterns. In addition, few studies using two or more genotyping methods to investigate clustered infected TB patients have been performed. In the present study, a greater diversity of spoligopatterns in the South, North and central zones of the city of Rio de Janeiro is noteworthy (Figure 3). The $\mathrm{T}$ lineage, one of the most prevalent genotypes in Africa, Central South and North America and Europe ${ }^{17}$, was the most frequent herein, corresponding to over one third $(36.6 \%)$ of the T1 sublineage (Figure 4 ).

Currently, the ubiquitous LAM clade is the major circulating lineage in $\mathrm{RJ}$, as described in a study carried out in 11 Brazilian States in which RJ contributed with $40 \%$ of all typed isolates, mainly obtained from hospitals (2000 to 2005), as well as with $65 \%$ of the LAM family ${ }^{20,21}$. In another study, the predominance of LAM $(69.4 \%)$ was observed when analyzing the M. tuberculosis structure population of TB patient prison inmates in the city of Rio de Janeiro (2005 to 2006), with the second largest cluster composed of LAM2/SIT179 isolates, and one $\mathrm{H}^{\mathrm{R} 22}$. Increments in global LAM burdens may be associated to MDR and extensive MDR, thus indicating the molecular monitoring as an important tool to understand the distribution of the molecular structure of mycobacterial strains in this setting $^{22}$. It is interesting to note that MDR belonging to the LAM2/SIT179 lineage in the present study was mainly drug resistant (Table 1), although 3' IS6110-RFLP patterns were different from those of the prison study. This suggests the importance of combining genotyping methods in a highTB burden area of a closed environment, such as a tertiary hospital or prison.

According to mathematical modeling studies, it is unlikely that drug-resistant isolates spread more easily than drug susceptible one ${ }^{23}$. In this retrospective study, although no epidemiological relationship was detected regarding $\mathrm{H}^{\mathrm{R}}$ patients, the findings may imply that these cases may have resulted from recent transmission, possibly from the home environment and/or social network, including primary multidrug resistant strains, as only two of the patients infected with drug-resistant $M$. tuberculosis underwent previous treatment. Moreover, the data corroborate other studies suggesting that all-major circulating families are associated to resistance in a given geographic area ${ }^{24,25}$. In a recent report concerning strains isolated from Veracruz, Southeastern Mexico, the $\mathrm{T}$ lineage was predominant and 8/10 samples of the T1 sublineage were SIT 53 multidrug-resistant ${ }^{26}$. Similarly, 47\% (27/58) of all drug resistant isolates detected in the present study belonged to the $\mathrm{T}$ superfamily, with $\mathrm{T} 1$ contributing to most cases $(22 / 27,78.6 \%)$. It is intriguing that, despite the prevalence of the ubiquitous SIT 53/T1 prototype, the evolutionary SIT 535, comprised 70\% of drug resistant strains (7/10) through the loss of three DR spaces. To the best of our knowledge, SIT 535 is not frequent in Brazil or in RJ in recent years ${ }^{20}$, although, as stated previously, genotyping studies are still scarce. Thus, this may suggest an endemic manner of transmission. 
Table 4 - Fingerprinting pattern of M. tuberculosis isolates from tertiary Pedro Ernesto University Hospital patients, grouped by 3' IS6110-RFLP and subdivided according to the 5' IS 6110-RFLP and the spoligotyping method.

\begin{tabular}{|c|c|c|c|c|c|}
\hline \multicolumn{6}{|c|}{ Molecular patterns by } \\
\hline \multicolumn{2}{|c|}{ 3' IS6110-RFLP } & \multicolumn{2}{|c|}{ 5' IS 6110-RFLP } & \multicolumn{2}{|r|}{ SPOLIGOTYPING } \\
\hline $\begin{array}{l}\text { Number of } \\
\text { clustered } \\
\text { patients }\end{array}$ & $\begin{array}{c}\text { (number of } \\
\text { bands) }\end{array}$ & $\begin{array}{l}\text { Number of } \\
\text { clustered } \\
\text { patients }\end{array}$ & $\begin{array}{c}\text { (number of } \\
\text { bands) }\end{array}$ & $\begin{array}{l}\text { Number of } \\
\text { clustered } \\
\text { patients }\end{array}$ & SIT (LINEAGES) \\
\hline 2 & \begin{tabular}{c|c||}
|||||||||| $\mid$ \\
11
\end{tabular} & 2 & ||$|1||1|||||||||$ & 0 & 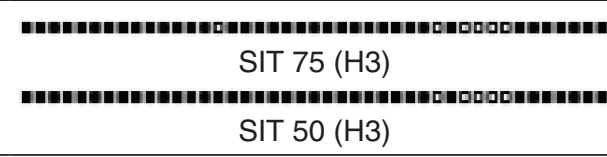 \\
\hline 2 &  & 2 & 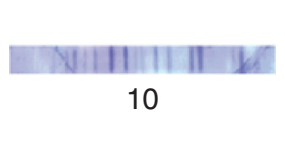 & 0 & 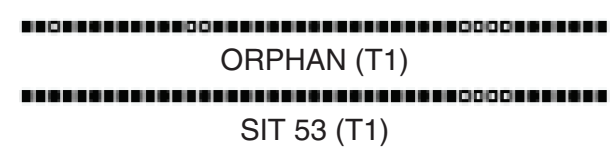 \\
\hline 4 & $|\quad|||||||$ & $\begin{array}{l}3 \\
0\end{array}$ & 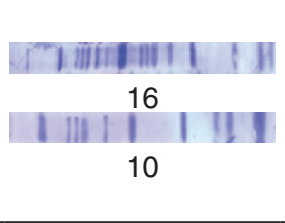 & 0 & $\begin{array}{l}\text { SIT179 (LAM2) } \\
\text { SIT } 50 \text { (H3) } \\
\text { SIT } 53 \text { (T1) }\end{array}$ \\
\hline 2 & 10 & 0 & 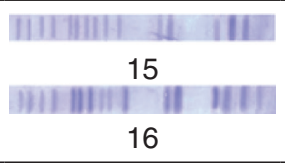 & 0 & $\begin{array}{l}\text { SIT2508 (UD) } \\
\text { SIT2557 (T1) }\end{array}$ \\
\hline 2 &  & 0 & 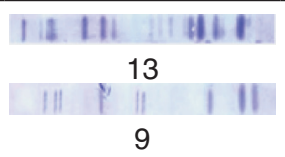 & 0 & $\begin{array}{l}\text { SIT } 535 \text { (T1) } \\
\text { SIT1905 (T1) }\end{array}$ \\
\hline 2 & $|\quad||||||||| \mid$ & 2 & | | ||||||||||| | | & 0 & $\begin{array}{l}\text { SIT } 1410 \text { (Ud) } \\
\text { SIT179 (LAM2) }\end{array}$ \\
\hline 5 & I 2 & 5 & $1 \mid 1 \quad 4$ & $\begin{array}{l}2 \\
0 \\
0 \\
0\end{array}$ & 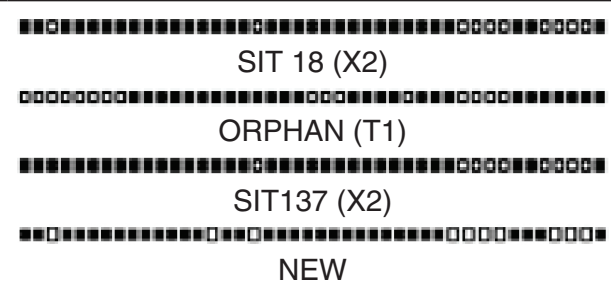 \\
\hline 2 & 7 & 2 & $\begin{array}{l}1+1 \mid+1 \\
8\end{array}$ & 2 & 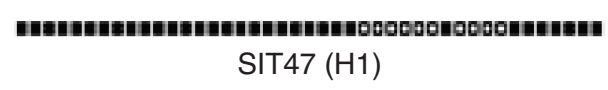 \\
\hline 2 & 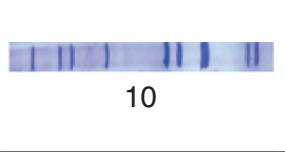 & 2 & | ||||||| & 0 & $\begin{array}{l}\text { SIT535 (T1) } \\
\text { SIT1905 (T1) }\end{array}$ \\
\hline 2 & 4 & 2 & \begin{tabular}{|l|l|}
11 & 1 \\
4 & 4
\end{tabular} & 0 & $\begin{array}{l}\text { SIT } 1410 \text { (Ud) } \\
\text { SIT } 535 \text { (T1) }\end{array}$ \\
\hline
\end{tabular}

Ud:Undefined; SIT: Spoligotype international typing

Another unusual genotype comprised high banding pattern X lineage strains. Unfortunately, the investigation of a mixed-clonal event in these patients was not possible, as only one culture sample was available, and both isolates did not grow in subcultures. However, recently GonzaloAsensio et al. ${ }^{27}$ have described a direct correlation between 
the normalized expression of IS6110 and the abundance of copies in MTBC chromosomes, including X lineage strains, varying from $<5$ to 14 copies. In this retrospective molecular analysis, although the gold standard 24 MIRU-VNTR method $^{28}$ was not applied, the 3' and 5' IS6110-RFLP methods defined clusters comprising isolates from different geographic areas and were able to disclose differences in the restriction fragment size pattern up to additional six fragments (Table 4). Furthermore, a partial lack of genotypic cluster similarity was detected by all methods, leading to decreased cluster frequency, indicating that the results may reflect fractions of a possible recent transmission from different communities. The significant $(\mathrm{p}=0.046)$ cluster associations with $\mathrm{H}^{\mathrm{R}}$ may support this hypothesis.

Recently, a one-year genotyping of $M$. tuberculosis isolated from the city of Porto, Portugal, by using 24 MIRU, found no evident chain of transmission of one or a limited number of specific genotypes ${ }^{29}$, a similar pattern to the HUPE strains observed herein, evidencing that multiple genotypes circulated in the urban area of Rio de Janeiro. Concerning the possible recent transmission episodes represented by HUPE clusters, no clear or classical epidemiological relationship could be established, as for the Porto study, suggesting a high genotypic structure diversity of M. tuberculosis circulating in the study area.

The present study presents certain limitations. Firstly, old samples and inadequate storage led to the unsuccessful subculture of many resistant strains. In addition, the 5' IS6110-RFLP method was performed only among strains clustered by 3' IS6110-RFLP. However, as proof of concept, this strategy was adequate. Finally, the study was carried out in a short timeframe, but this is justified by the fact that it is part of an earlier cross-sectional study. Despite this, and the fact that RFLP is more time-consuming and cumbersome than MIRU-VNTR, the RFLP method disclosed unsuspected and possibly transmitted infections aside from mixed infections, including for MDR strains. Immunodeficient and immunocompetent individuals may be infected with more than one strain during the same disease episode (mixed infection), or reinfected by a second M. tuberculosis strain during recurrent episodes (exogenous reinfection) ${ }^{30}$. Huyen et al. ${ }^{31}$ reported $3.1 \%$ of mixed infections by combining RFLP and spoligotyping in a rural area of Vietnam, equal frequency of our study, using both methods. Another study carried out a retrospective genotyping in previously samples suspected of having epidemiological relationships ${ }^{32}$, which in contrary to the present study, they described a slightly more adequate RFLP cluster results compared to MIRU-VNTR ${ }^{32,33}$. Additionally, RFLP lacks the discriminatory power for strains presenting less than six banding patterns, while spoligotyping and MIRU-VNTR are more adequate in this regard. Herein, only $2 / 7$ low banding strains were clustered by all applied genotypic methods, displaying the same drug resistance, suggesting a possible transmission, although no epidemiological relationship was detected (Tables 3 and 4). According to Jonsson et al..$^{32}$, clustering is an important finding, but not a crucial evidence of true relationships.

In conclusion, despite being time-consuming, the 3' - 5' IS6110-RFLP and spoligotyping techniques revealed an association risk and unsuspected past epidemiological events. In fact, the success of this study relies on available epidemiological data information. This study may, therefore, serve as a database for further evolutionary and characterization evaluation of circulating strains and, along with epidemiological data, may aid in more effective transmission control measures, mainly in close settings.

\section{AUTHORS' CONTRIBUTIONS}

SMA: responsible for the implementation of the study in all phases of technical and experimental development as well as in the collection and statistical analysis of the data obtained and the preparation of the manuscript. ACM: collaborated in the analysis of the results of genotyping. CQFL: supervised the implementation of the genotyping methods and the analysis of the results of genotyping. MHFS: designed the study, supervised all stages of the implementation and study development, wrote and reviewed the manuscript. All authors contributed to the interpretation of the results and the revision of the manuscript.

\section{ACKNOWLEDGMENTS}

The authors are deeply grateful to Rossana Coimbra de Brito from the Hospital Federal Servidores do Estado do Rio de Janeiro, Rio de Janeiro, Dirce Bonfim de Lima from the Hospital Universitário Pedro Ernesto, Universidade Estadual do Rio de Janeiro, Rio de Janeiro, and Afranio Lineu Kritsk from the Universidade Federal do Rio de Janeiro/Hospital Clementino Fraga Filho, Rio de Janeiro for their valuable comments.

\section{REFERENCES}

1. World Health Organization. Global tuberculosis report 2018. Geneva: WHO; 2018. [cited 2019 Apr 18]. Available from: http://www.who.int/iris/handle/10665/274453

2. Brasil. Ministério da Saúde. Secretaria de Vigilância em Saúde. Perspectivas brasileiras para o fim da tuberculose como problema de saúde pública. Bol Epidemiol. 2016;47:1-15. 
3. Instituto Brasileiro de Geografia e Estatística. Rio de Janeiro. [cited 2019 Apr 18]. Available from: https://cidades.ibge.gov. br/brasil/rj/rio-de-janeiro/panorama

4. Brasil. Ministério da Saúde. Secretaria de Vigilância em Saúde. Implantação do Plano Nacional pelo Fim da Tuberculose como Problema de Saúde Pública no Brasil: primeiros passos rumo ao alcance das metas. Bol Epidemiol. 2018;49:1-18.

5. Brito RC, Gounder C, Lima DB, Siqueira H, Cavalcanti HB, Pereira MP, et al. Drug-resistant Mycobacterium tuberculosis strains isolated at an AIDS reference center general hospital in Rio de Janeiro. J Bras Pneumol. 2004;30:425-32.

6. Vasconcelos G, Dias SM, Oliveira HM, Bellizi AL, Kritski AL. Características dos casos de tuberculose nos centros municipais de saúde e hospitais no município do Rio de Janeiro em 1995. J Pneumol. 1996;22:104.

7. Yang ZH, Bates JH, Eisenach KD, Cave MD. Secondary typing of Mycobacterium tuberculosis from different geographic regions of United States. J Clin Microbiol. 2001;39:1691-5.

8. van Embden JD, Cave MD, Crawford JT, Dale JW, Eisenach $\mathrm{KD}$, Gicquel B, et al. Strain identification of Mycobacterium tuberculosis by DNA fingerprinting: recomendations for a standardized methodology. J Clin Microbiol. 1993;31:406-9.

9. de Boer AS, Borgdorff MW, de Haas PE, Nagelkerke NJ, van Embden JD, van Soolingen D. Analysis of rate of change of IS6110 RFLP-IS6110 patterns of Mycobacterium tuberculosis based on serial patient isolates. J Infect Dis. 1999;180:1238-44.

10. Brasil. Ministério da Saúde. Secretaria de Vigilância da Saúde. Centro de Referência Professor Hélio Fraga. Manual de bacteriologia da tuberculose. $3^{\mathrm{a}}$ ed. Rio de Janeiro: Ministério da Saúde; 2005.

11. van Soolingen D, de Haas PE, Hermans PW, van Embden JD. DNA fingerprinting of Mycobacterium tuberculosis. Methods Enzymol. 1994;235:196-205.

12. Abadia D, Zhang J, Ritacco V, Kremer K, Ruimy R, Rigouts $\mathrm{L}$, et al. The use of microbead-based spoligotyping for Mycobacterium tuberculosis complex to evaluate the quality of the conventional method: providing guidelines for Quality Assurance when working on membranes. BMC Infect Dis. 2011;11:110.

13. Kamerbeek J, Schouls L, Kolk A, van Agterveld M, van Soolingen D, Kuijper S, et al. Simultaneous detection and strain differentiation of Mycobacterium tuberculosis for diagnosis and epidemiology. J Clin Microbiol. 1997;35:907-14.

14. Saad MH, Fonseca LS, Ferrazoli L, Fandinho F, Palaci M, Grinsztejn B, et al. IS1245 genotypic analysis of Mycobacterium avium isolates from patients in Brazil. Int $\mathrm{J}$ Infect Dis. 1999;3:192-6.

15. Lari N, Rindi L, Lami C, Garzilli C. IS6110-based restriction fragment length polymorphism (RFLP) analysis of Mycobacterium tuberculosis H37Rv and H37Ra. Microbiol Pathog. 1999;26:281-6.
16. Gebeyehu G, Rao PY, SooChan P, Simms DA, Klevan L. Novel biotinylated nucleotide-analogs for labeling and colorimetric detection of DNA. Nucleic Acids Res. 1987;15:4513-34.

17. Couvin D, Rastogi N. Tuberculosis - a global emergency: tools and methods to monitor, understand, and control the epidemic with specific example of the Beijing lineage. Tuberculosis (Edinb). 2015;95 Suppl 1:S177-89.

18. Demay C, Liens B, Burguière T, Hill V, Couvin D, Millet J, et al. SITVITWEB: a publicly available international multimarker database for studying Mycobacterium tuberculosis genetic diversity and molecular epidemiology. Infect Genet Evol. 2012;12:755-66.

19. Hunter PR, Gaston MA. Numerical index of the discriminatory ability of typing systems: an application of Simpson's index of diversity. J Clin Microbiol. 1988:26:2465-6.

20. Gomes HM, Elias AR, Oelemann MA, Pereira MA, Montes FF, Marsico AG, et al. Spoligotypes of Mycobacterium tuberculosis complex isolates from patients residents of 11 states of Brazil. Infect Genet Evol. 2012;12:649-56.

21. Lazzarini LC, Huard RC, Boechat NL, Gomes HM, Oelemann MC, Kurepina N, et al. Discovery of a novel Mycobacterium tuberculosis lineage that is a major cause of tuberculosis in Rio de Janeiro, Brazil. J Clin Microbiol. 2007;45:3891-902.

22. Huber FD, Sánchez A, Gomes HM, Vasconcellos S, Massari $\mathrm{V}$, Barreto A, et al. Insight into the population structure of Mycobacterium tuberculosis using spoligotyping and RDRio in a southeastern Brazilian prison unit. Infect Genet Evol. 2014;26:194-202.

23. Panwalkar N, Chauhan DS, Desikan P. Spoligotype defined lineages of Mycobacterium tuberculosis and drug resistance: merely a casual correlation? Indian J Med Microbiol. 2017;35:27-32.

24. Dye C, Williams BG, Espinal MA, Raviglione MC. Erasing the world's slow stain: strategies to beat multidrug-resistant tuberculosis. Science. 2002;295:2042-6.

25. Mokrousov I, Vyazovaya A, Otten T, Zhuravlev V, Pavlova E, Tarashkevich L, et al. Mycobacterium tuberculosis population in Northwestern Russia: an update from Russian-EU/Latvian border region. PLoS One. 2012;7: e41318.

26. Munro-Rojas D, Fernandez-Morales E, Zarrabal-Meza J, Martínez-Cazares MT, Parissi-Crivelli A, Fuentes-Dominguez $\mathrm{J}$, et al. Genetic diversity of drug and multidrug-resistant Mycobacterium tuberculosis circulating in Veracruz, Mexico. PLoS One. 2018;13:e0193626.

27. Gonzalo-Asensio J, Pérez I, Aguiló N, Uranga S, Picó A, Lampreave C, et al. New insights into the transposition mechanisms of IS6110 and its dynamic distribution between Mycobacterium tuberculosis Complex lineages. PLoS Genet. 2018;14:e1007282.

28. Supply P, Allix C, Lesjean S, Oelemann MC, Rüsch-Gerdes S, Willery E, et al. Proposal for standardization of optimized 
mycobacterial interspersed repetitive unit-variable-number tandem repeat typing of Mycobacterium tuberculosis J Clin Microbiol. 2006;44:4498-510.

29. Rito T, Matos C, Carvalho C, Machado H, Rodrigues G, Oliveira $\mathrm{O}$, et al. A complex scenario of tuberculosis transmission is revealed through genetic and epidemiological surveys in Porto. BMC Infect Dis. 2018;18:53

30. Warren RM, Victor TC, Streicher EM, Richardson M, Beyers N, Gey Van Pittius NC, et al. Patients with active tuberculosis often have different strains in the same sputum specimen. Am J Respir Crit Care Med. 2003;169:610-4.
31. Huyen MN, Kremer K, Lan NT, Cobelens FG, Buu TN, Dung NH, et al. Mixed tuberculosis infections in rural South Vietnam. J Clin Microbiol. 2012;50: 1586-92.

32. Jonsson J, Hoffner S, Berggren I, Bruchfeld J, Ghebremichael $\mathrm{S}$, Pennhag A, et al. Comparison between RFLP and MIRUVNTR genotyping of Mycobacterium tuberculosis strains isolated in Stockholm 2009 to 2011. PLoS One. 2014:9:e95159.

33. Augusto CJ, Carvalho WS, Almeida IN, Figueiredo LJ, Dantas NG, Suffys PN, et al. Comparative study of RFLP-IS6110 and MIRU-VNTR from Mycobacterium tuberculosis isolated in the state of Minas Gerais, Brazil. Braz J Microbiol. 2018;49:641-6. 